\title{
Determination of the South China Sea Surface Height Variability Using TOPEX/POSEIDON data
}

\author{
Peter C. Chu, Naval Ocean Analysis and Prediction Laboratory \\ Department of Oceanography, Naval Postgraduate School, Monterey, CA 93943, USA \\ Jing Wang, and Yiquan Qi, Institute of the South China Sea Oceanology, Guangzhou, China
}

\begin{abstract}
The monthly mean TOPEX/POSEIDON crossover data in the South China Sea are used to investigate the spatial and temporal variability of sea surface height anomaly (SSHA). Multi-time scale variability is found using the empirical orthogonal function (EOF) analysis. The seasonal variability dominates SSHA with two spatial patterns: basin-wide gyre and north-south double gyres. The intraseasonal variability of SSH has high spatial variability at the continental shelf such as west of Hainan Island and Borneo, and east-west double gyre structure in the deep basin. The interannual variability of SSHA has a north-south double gyre pattern. The scale interaction between seasonal and interannual processes may be taken place at the north-south double gyre pattern.
\end{abstract}

Keywords: TOPEX/POSEIDON altimetry, South China Sea, empirical orthogonal functions, seasonal, intraseasonal, interannual variability

\section{INTRODUCTION}

The South China Sea (SCS) is a semi-enclosed tropical and sub-tropical sea located between the Asian landmasses (including Taiwan) to the west and north, the Philippines Islands to the east and Malaysia and Borneo to the south (Figure 1), a total of $3.5 \times 10^{6} \mathrm{~km}^{2}$ surface area. It includes the shallow Gulf of Thailand and connections to the East China Sea (through the Taiwan Strait), the Pacific Ocean (through the Luzon Strait), the Sulu Sea (through the Balabac Strait), the Java Sea (through the Gasper and Karimata Straits) and to the Indian Ocean (through the Strait of Malacca). All of these straits are shallow except the Luzon Strait whose maximum depth is $1800 \mathrm{~m}$. Consequently the SCS is considered a semi-enclosed water body. The complex topography includes the broad shallows of the Sunda Shelf in the south and southwest; the continental shelf of the Asian landmass in the west and north, extending from the Gulf of Tonkin to the Taiwan Strait; a deep, elliptical shaped basin in the center, and numerous reef islands and underwater plateaus scattered throughout. The shelf that extends from the Gulf of Tonkin to the Taiwan Strait is consistently about $70 \mathrm{~m}$ deep, and averages $150 \mathrm{~km}$ in width from the shoreline; the central deep basin is $1900 \mathrm{~km}$ along its major axis (northeast-southwest) and approximately $1100 \mathrm{~km}$ along its minor axis, and extends to over $4000 \mathrm{~m}$ deep. The Sunda Shelf is the submerged connection between Southeast Asia, Malaysia, Sumatra, Java and Borneo and is $100 \mathrm{~m}$ deep in the middle; the Gulf of Thailand is about $70 \mathrm{~m}$ deep in its central part.

The observed circulation patterns of the intermediate to upper layers of the SCS are also primarily forced by the local monsoon systems. Based on limited data, Wyrtki (1961) constructed the surface circulation pattern. From April to August, the weaker southwesterly summer monsoon winds result in a wind stress of over $0.1 \mathrm{~N} / \mathrm{m}^{2}$ (Figure 2a), which drives a northward coastal jet off Vietnam and an anticyclonic circulation in the central SCS. From November to March, the stronger northeasterly winter monsoon winds corresponding to a maximum wind stress of nearly $0.2 \mathrm{~N} / \mathrm{m}^{2}$ (Figure $2 b$ ) causing a southward coastal jet off Vietnam and a cyclonic circulation in the central SCS. Transitional periods are highly variable winds and surface currents. The current meter observation in SCS is very sparse. It is very hard to get spatial and temporal variability of the SCS circulation from in-situ data. Sea surface elevation anomaly data from the TOPEX/POSEIDON (T/P) provide useful information about the surface circulation. 


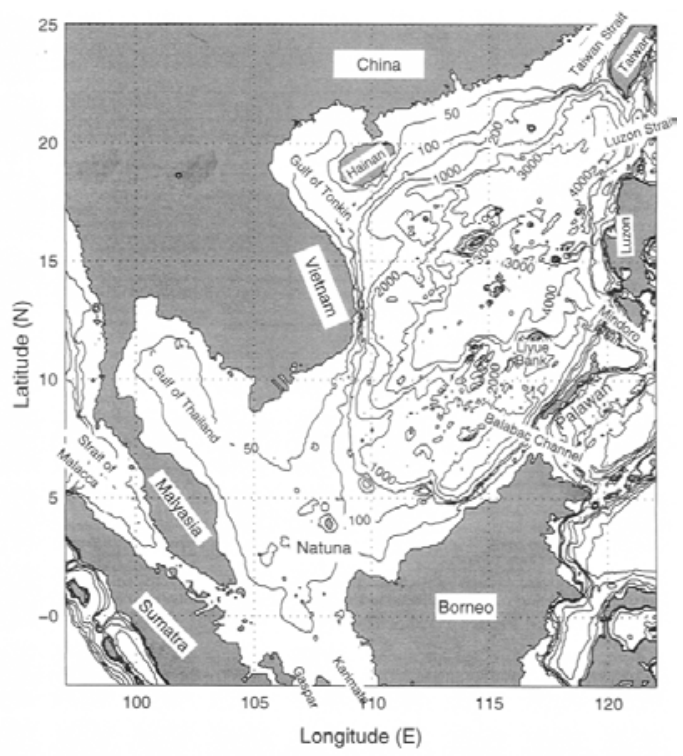

Figure 1. Geography and isobaths showing the bottom topography of the South China Sea.

(a)

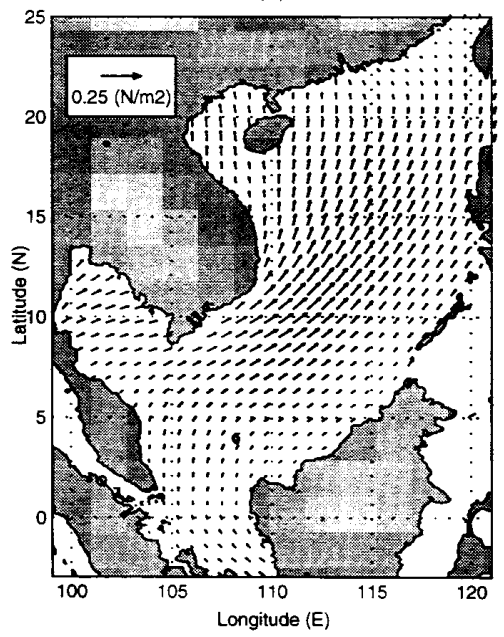

(b)

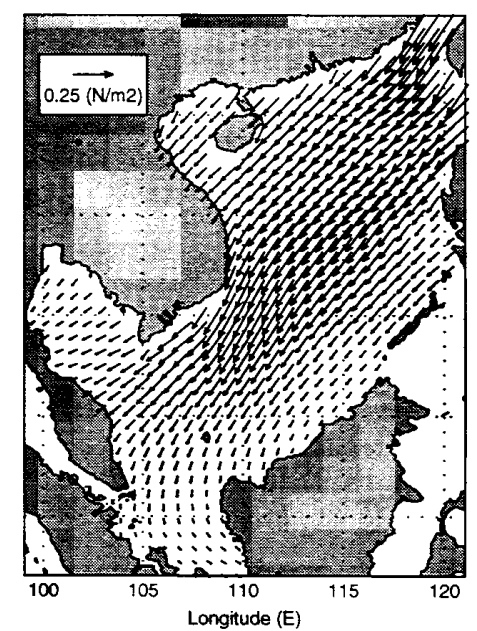

Figure 2. Climatological wind stress for (a) June and (b) December (After Hellerman and Rosenstein 1983).

\section{TOPEX/POSEIDON}

T/P is a joint venture by NASA and the French space Centre National d'Etues Spatiales (CNES) that is designed to produce global maps of ocean surface topography (Stewart et al., 1986). The data used in this study are from October 1992 to September 1999 (257 cycles). There are 24 crossover points over SCS (Figure 3). After removing the tides, the monthly mean values ( 84 months all together) are calculated for each crossover point. 


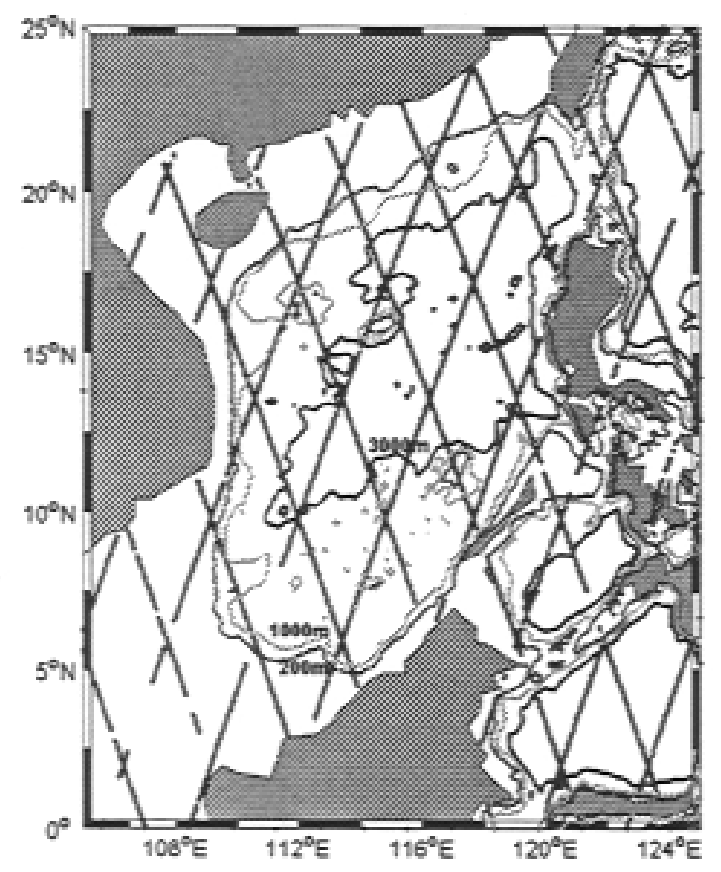

Figure 3. T/P Tracks over the South China Sea.

\section{EMPIRICAL ORTHOGONAL FUNCTION (EOF) ANALYSIS}

\subsection{Principle EOF Modes}

The monthly sea surface height anomaly (SSHA) data from T/P form an $\mathrm{N} \times \mathrm{P}$ matrix. Here $\mathrm{P}=84$, is the total number of time points used for computing the covariance matrix. $\mathrm{N}=24$, corresponds to the number of crossover points. Empirical Orthogonal Function (EOF) analysis (Lorenz, 1956) widely used in oceanographic and meteorological research is the same as Principal Component (PC) Analysis (Hotelling, 1933) in the statistics community. PCs are the amplitudes, which are functions of time, of their corresponding EOFs. These EOFs can be found by calculating the unitary eigenvectors of the covariance matrix associated with the sample data field. EOF analysis separates the data sets into eigenmodes. Generally speaking, each mode has an associated variance, nondimensional spatial pattern, and dimensional time series. Therefore, we have 84 time points in the EOF analysis. From this data matrix a 24 -square spatial covariance matrix is calculated.

SSHA can be quantitatively investigated with the method of EOF analysis and a number of its generalized forms. In order to delineate the major modes of variability, we perform an EOF analysis using the method outlined in Section 3 and obtain the first five leading EOFs, which are able to account for almost $66.9 \%$ of the total variance during the seasons (Table 1). When combined EOF1, EOF2 and EOF3 explain near half (49.5\%) of the total variance. Each EOF mode is normalized so that its total spatial variance is equal to unity. So, those patterns of the first five EOFs are enough to explain the spatial anomalies of the whole SCS. Hence, it suffices to focus on the first five EOFs.

\subsection{EOF1}

The EOF1 mode (Figure 4a) shows a basin-scale SSHA structure with high values (larger that 0.1) in the SCS deep basin and low values near Chinese and Vietnamese coast. The surface circulation corresponding to EOF1 is a basin-scale gyre. To identify the gyre is cyclonic or anticyclonic, we should consider the product of the EOF values and the corresponding time series of the amplitudes, also called PC components. 
The first principal component, $\mathrm{PC}_{1}$, for October 1992 - September 1999 is shown in Figure $4 \mathrm{~b}$. The time series of $\mathrm{PC}_{1}$ (Figure $4 \mathrm{~b}$ ) shows the seasonal variability. The Fourier analysis on $\mathrm{PC}_{1}$ shows the existence of a strong peak at one year's period (Figure 4c). During the winter monsoon season, $\mathrm{PC}_{1}>0$, the first mode shows positive SSHA in the SCS deep basin, which implies an anticyclonic gyre in SCS. During the summer monsoon season, $\mathrm{PC}_{1}<0$, the first mode shows negative SSHA in the SCS deep basin, which implies a cyclonic gyre.

Table 1. Variances of the First Five Leading EOFs

\begin{tabular}{|l|l|l|}
\hline EOF & Variance (\%) & $\begin{array}{l}\text { Cumulative } \\
\text { Variance (\%) }\end{array}$ \\
\hline 1 & 24.16 & 24.16 \\
\hline 2 & 14.59 & 38.75 \\
\hline 3 & 10.76 & 49.51 \\
\hline 4 & 6.77 & 56.28 \\
\hline 5 & 5.04 & 61.32 \\
\hline
\end{tabular}
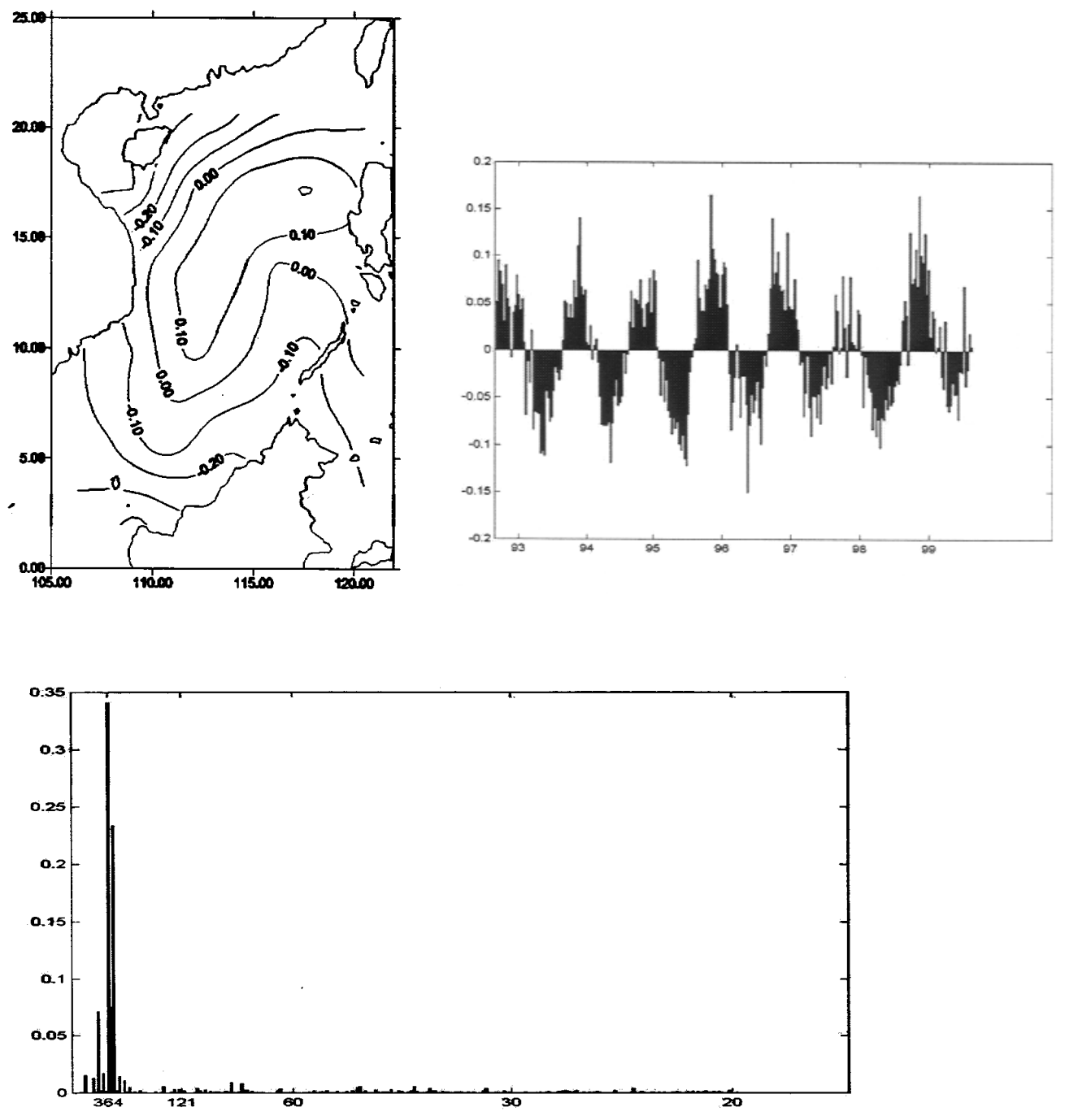

Figure 4. (a) The EOF1 mode (unit: $\mathrm{cm}$ ), (b) time series of $\mathrm{PC}_{1}$, and (c) Fourier spectrum of $\mathrm{PC}_{1}$. 


\subsection{EOF2}

The EOF2 mode (Figure 5a) shows double-gyre structure with a high center in the southern SCS (south of $10^{\circ} \mathrm{N}$ ) and a low center in the northern SCS (north of $10^{\circ} \mathrm{N}$ ). To identify each gyre is cyclonic or anticyclonic, we should consider the product of the EOF2 values and the corresponding time series of $\mathrm{PC}_{2}$.

The second principal component, $\mathrm{PC}_{2}$, for October 1992 - September 1999 is shown in Figure 5b. The Fourier analysis on $\mathrm{PC}_{2}$ shows the existence of a strong peak (0.48) at one year's period. During the winter monsoon season, $\mathrm{PC}_{2}<0$, the second mode shows low SSHA center in the southern SCS and high SSHA center in the northern SCS, which implies a cyclonic gyre in the southern SCS and an anticyclonic gyre in the northern SCS. During the summer monsoon season, $\mathrm{PC}_{2}>0$, the second mode shows high SSHA center in the southern SCS and low SSHA center in the northern SCS, which implies an anticyclonic gyre in the southern SCS and a cyclonic gyre in the northern SCS.

Besides the seasonal variability, $\mathrm{PC}_{2}$ has a second peak (0.07) at 849 days (around 2 years 10 months). Since the data length is 7 years. This indicates that the interannual variability contains EOF2 pattern (north-south double gyres).
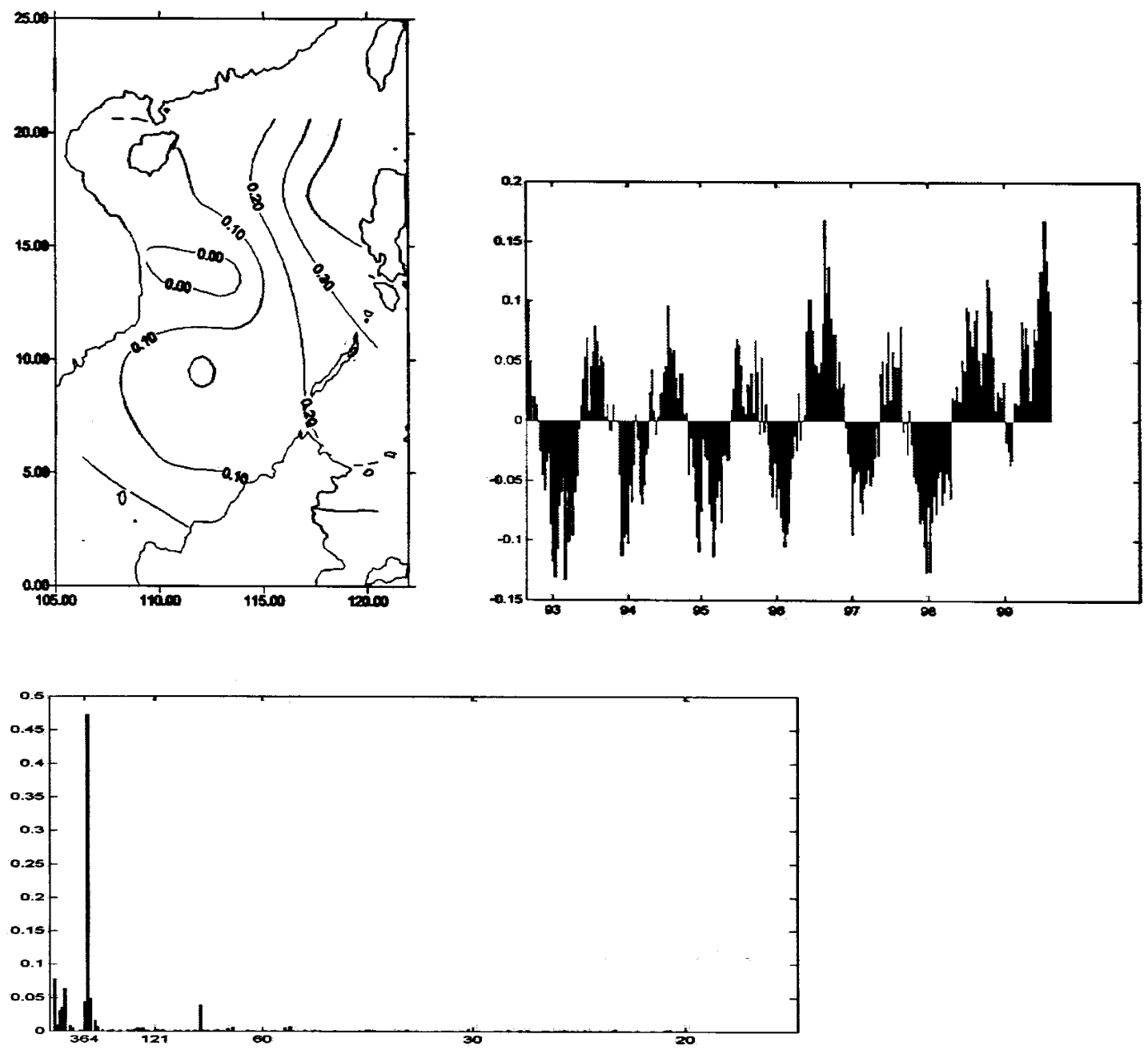

Figure 5. (a) The EOF2 mode (unit: cm), (b) time series of $\mathrm{PC}_{2}$, and (c) Fourier spectrum of $\mathrm{PC}_{2}$. 


\subsection{EOF3}

The EOF3 mode (Figure 6a) shows weak spatial variability (east-west gyres) in the SCS deep basin and high spatial variability at the continental shelf such as west of Hainan Island and Borneo. The third principal component, $\mathrm{PC}_{3}$, for October 1992 - September 1999 is shown in Figure 6b. The Fourier analysis on $\mathrm{PC}_{3}$ (Figure 6c) shows the existence of a strong peak (0.08) at 46days (intraseasonal time scale). Thus, the evident intraseasonal variability of SSHA occurs in the continental shelf region.
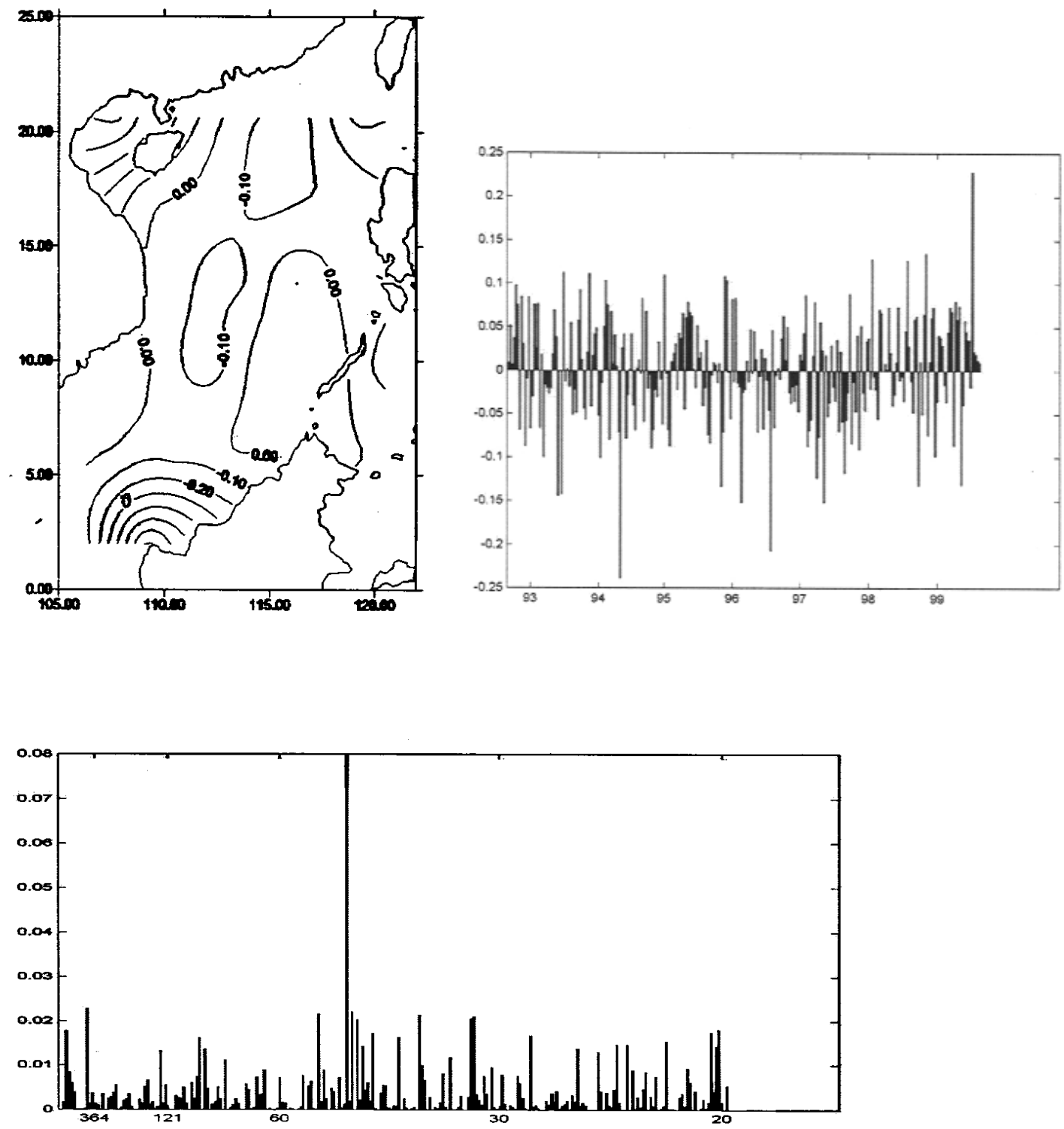

Figure 6. (a) The EOF3 mode (unit: cm), (b) time series of $\mathrm{PC}_{3}$, and (c) Fourier spectrum of $\mathrm{PC}_{3}$. 


\subsection{EOF4}

The EOF4 mode (Figure 7a) shows double-gyre structure with a low center in the southern SCS (south of $10^{\circ} \mathrm{N}$ ) and a high center in the northern SCS (north of $10^{\circ} \mathrm{N}$ ). This mode is similar to EOF2 mode. The time series of $\mathrm{PC}_{4}$, for October 1992 - September 1999, is shown in Figure 7b. The Fourier analysis on $\mathrm{PC}_{4}$ (Figure 7c) shows the existence of a strong peak (0.15) at 1019 days (around 2 years 10 months). Thus, the evident interannual variability of SSHA reveals the north-south double gyre structure. The second peak (0.11) is located at 340 days (seasonal variability).
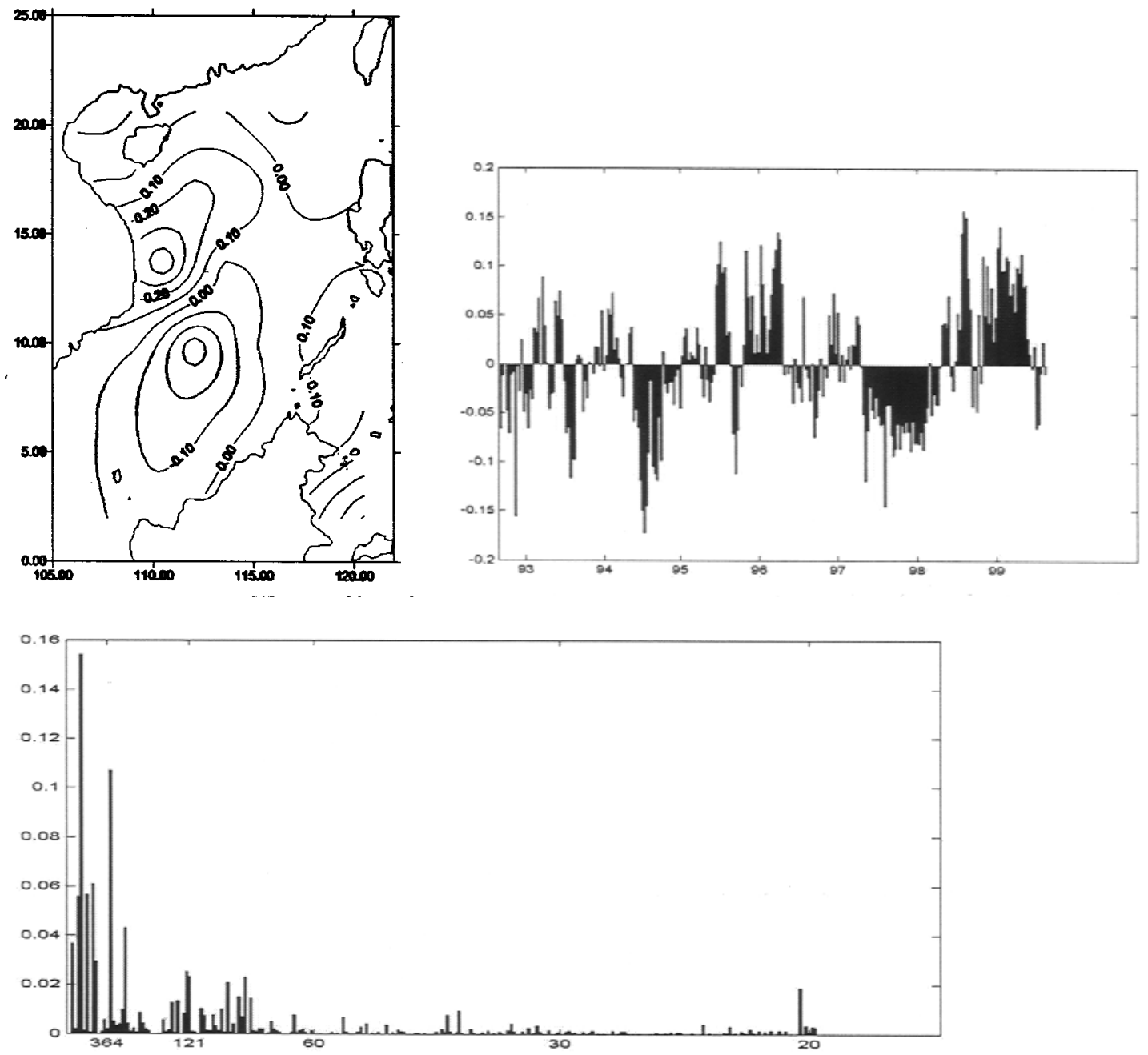

Figure 7. (a) The EOF4 mode (unit: cm), (b) time series of $\mathrm{PC}_{4}$, and (c) Fourier spectrum of $\mathrm{PC}_{4}$. 


\subsection{EOF5}

The EOF5 mode (Figure 8a) shows high spatial variability at the continental shelf such as west of Hainan Island and Borneo, and east-west double gyre structure in the deep basin. The fifth principal component, $\mathrm{PC}_{5}$, for October $1992-$ September 1999 is shown in Figure 8b. The Fourier analysis on $\mathrm{PC}_{5}$ (Figure 8c) shows the existence of a strong peak (0.16) at 85 days (intraseasonal time scale).
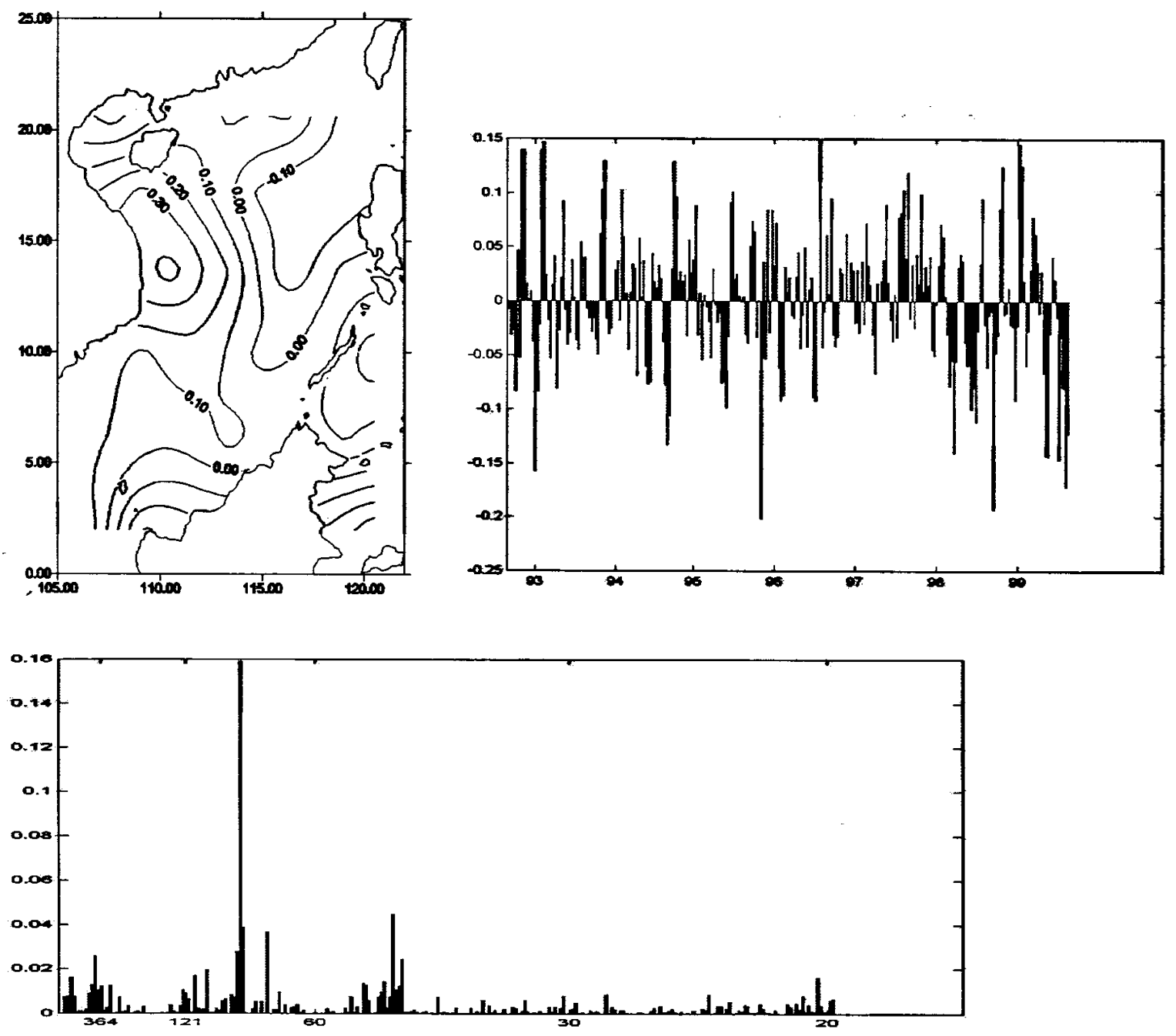

Figure 8. (a) The EOF5 mode (unit: cm), (b) time series of $\mathrm{PC}_{5}$, and (c) Fourier spectrum of $\mathrm{PC}_{5}$.

\section{MULTI-SCALE VARIABILITY}

T/P data show the existence of seasonal, intraseasonal, and interannual variabilities of SSHA.

\subsection{Seasonal Variability}

Seasonal variability dominates SSHA with two spatial patterns: basin-wide gyre (EOF1) and north-south double gyres (EOF2 and EOF4). The seasonal variability of basin-wide gyre is: an anticyclonic gyre during the winter monsoon season, and a cyclonic gyre during the summer monsoon season. The seasonal variability of north-south double gyre is: 
a cyclonic gyre in the southern SCS and an anticyclonic gyre in the northern SCS during winter monsoon season, and an anticyclonic gyre in the southern SCS and a cyclonic gyre in the northern SCS during the summer monsoon season.

\subsection{Interannual Variability}

Interannual variability of SSHA has a north-south double gyre pattern (EOF2 and EOF4). Since this pattern experiences both seasonal and interannual variabilities, the scale interaction between seasonal and interannual processes may be taken place at this spatial pattern, which is the out-of-phase of SSHA in northern and southern SCS (increase of SSH in northern SCS and decrease of SSH in the southern SCS, and vice versa).

\subsection{Intraseasonal Variability}

Intraseasonal variability of SSH has high spatial variability at the continental shelf such as west of Hainan Island and Borneo, and east-west double gyre structure in the deep basin (EOF3 and EOF5). Shelf processes are major sources for the intraseasonal variability.

\section{CONCLUSIONS}

The EOF analysis was applied to the monthly mean T/P crossover data in the South China Sea to investigate the spatial and temporal variabilities of SSHA. Our study shows the existence of multi-time scale variability: seasonal, interannual, and intraseasonal. Following results were obtained.

(1) Seasonal variability dominates SSHA with two spatial patterns: basin-wide gyre and north-south double gyres.

(2) Interannual variability of SSHA has a north-south double gyre pattern.

(3) Intraseasonal variability of SSH has high spatial variability at the continental shelf such as west of Hainan Island and Borneo, and east-west double gyre structure in the deep basin.

(4) Scale interaction between seasonal and interannual processes may be taken place at the north-south double gyre pattern.

\section{ACKNOWLEDGMENTS}

Authors are grateful to Chenwu Fan for programming assistance. This work was funded by the Naval Oceanographic Office, and the Naval Postgraduate School.

\section{REFERENCES}

Chu, P.C., H. C. Tseng, C.P. Chang, and J.M. Chen, South China Sea warm pool detected in spring from the Navy's Master Oceanographic Observational Data Set (MOODS). J. Geophys. Res., 102, 15,761-15,771, 1997a.

Chu, P.C., S.H. Lu, and Y.C. Chen, Temporal and spatial variabilities of the South China Sea surface temperature anomaly. J. Geophys. Res., 102, 20,937-20,955, $1997 \mathrm{~b}$.

Chu, P.C., S.K. Wells, S.D. Haeger, C. Szczechowski, and M. Carron, Temporal and spatial scales of the Yellow Sea thermal variability. J. Geophys. Res., 102, 5,655-5,667, $1997 \mathrm{c}$.

Chu, P.C., N.L. Edmons, and C.W. Fan, Dynamical mechanisms for the South China Sea seasonal circulation and thermohaline variabilities. J. Phys. Oceanogr., 29, 2,971-2,989, 1999 a.

Chu, P.C., S.H. Lu, and W.T. Liu Uncertainty of the South China Sea prediction using NSCAT and NCEP winds during tropical storm Ernie 1996. J. Geophys. Res., 104, 11,273-11,289, 1999b. 
Nitani, H., Oceanographic conditions in the sea east of Philippines and Luzon Strait in summer of 1965 and 1966, The Kuroshio-A Symposium on Japan Current, edited by J.D. Marr, pp. 213-232, East-West Press, Honolulu, Hawaii, 1970.

Qiu, D.Z., Y.T. Huang, L.M. Chen, and Z.X. Guo, Circulation structures in the studied waters. Comprehensive Investigations and Studies of the South China Sea, Vol 2, Science Press, Beijing, pp. 204-230, in Chinese, 1985.

South China Sea Institute of Oceanology, Integrated Investigation Report on Sea Area of the South China Sea (in Chinese), Vol. 2, pp. 183-231, Science Press, Beijing, 1985.

Wu, C.R., P.T. Shaw, and S.Y. Chao,: Assimilating altimetric data into a South China Sea model. J. Geophys. Res., 104, 29987-30005, 1999.

Wyrtki, K., Scientific results of marine investigations of the South China Sea and Gulf of Thailand 1959-1961, Naga Rep., 2, pp. 164-169, Scripps Institution of Oceanography, University of California, San Diego, $1961 .$. 